\title{
Study on the Antioxidant Activity of Grape Stems (Vitis vinifera). A Preliminary Assessment of Crude Extracts
}

\author{
Antonia Llobera \\ Department of Chemistry, University of Illes Balears, Palma de Mallorca, Spain. \\ Email: antonia.1lobera@uib.es \\ Received May $27^{\text {th }}, 2011$; revised February $27^{\text {th }}, 2012$; accepted March $4^{\text {th }}, 2012$
}

\begin{abstract}
The antioxidant activity of $80 \%$ ethanol and $70 \%$ acetone extracts of stems from red and white grapes (Vitis vinifera) used in wine industry were evaluated to determine their feasibility as natural antioxidants. The results showed that all grape stem extracts were rich in total polyphenolic compounds and flavanols and had clear antioxidant activities. The free radical-scavenging capacity of the extracts was determined using the DPPH (2,2-diphenyl-1-picrylhydrazyl) method. The extracts obtained from red grape stem present $\mathrm{EC}_{50}$ values of $0.14 \mathrm{~g} \mathrm{dm} / \mathrm{g}$ DPPH (acetone extract) and 0.20 $\mathrm{g} \mathrm{dm} / \mathrm{g} \mathrm{DPPH} \mathrm{(ethanol} \mathrm{extract)} \mathrm{while} \mathrm{the} \mathrm{extracts} \mathrm{obtained} \mathrm{from} \mathrm{white} \mathrm{grape} \mathrm{stem} \mathrm{present} \mathrm{EC}_{50}$ values of $0.26 \mathrm{~g} \mathrm{dm} / \mathrm{g}$ DPPH (acetone extract) and $0.37 \mathrm{~g} \mathrm{dm} / \mathrm{g}$ DPPH (ethanol extract). There are significant correlations between the total content of polyphenols and the antioxidant activity $\left(\mathrm{R}^{2}=0.9352\right)$ and between the flavanols content and the antioxidant activity $\left(\mathrm{R}^{2}=0.9404\right)$ of the grape stem extracts obtained.
\end{abstract}

Keywords: Grape Stem; Antioxidant Activity; Stem Extracts; Polyphenols; Radical Scavenging Activity; DPPH

\section{Introduction}

There is a growing interest in the exploitation of the residues generated by the food industry, and this is very attractive to the vegetable/beverage industry, as they will have to sustain increasing costs for treating these solid and liquid wastes. This is particularly true in wine production, which affords a substantial volume of solid organic material. The main by-products are collected during de-stemming (stems) and pressing (pomace). At present, only minimum amounts of these wastes are recycled and this is definitely the case in Europe, where vegetable wastes are generally used for animal feed or compost, without any pre-treatment. Specifically, in grape and wine production zones, a great quantity of residues is generated with little economic interest and is associated with environmental waste issues. Numerous studies indicate that wine, grapes and pomaces contain significant amounts of polyphenolic compounds although less attention has been paid to grape stems, despite that these contain important amounts of polyphenols [1-4]. Furthermore, phenolic constituents present in grapes have aroused great interest due to their antioxidant properties and putative health-promoting effects. Antioxidant compounds are used to prevent or reduce food product deterioration and human degenerative diseases [5]. Free radicals have been claimed to play a key role, in affecting human health by causing life-threatening illnesses by cell degeneration, such as cancer and cardiovascular diseases. These free radicals can be generated during normal body function, and can be acquired from the environment. Polyphenols are known to be powerful antioxidants as they are hydrogen donating free radical scavengers [6-9].

Therefore, a study of grape by-products such as stems as a possible source of derivatives with antioxidant polyphenolic compounds is of interest, as any useful production from this by-product could represent an economic revaluation of the raw material and an interesting advance in the prevention or reduction of environmental problems caused by residue generation.

The objective of this present study was to evaluate the antioxidant activity of direct stem extracts from red and white grapes (Vitis vinifera) used in the wine industry to examine their utilization as natural antioxidants. In addition, correlations between total polyphenolic and flavanol content and antioxidant activity were also evaluated.

\section{Materials and Methods}

\subsection{Materials and Chemicals}

The samples correspond to the stems of the winemaking processes of Manto Negro red grape and Prensal Blanc white grape (Vitis vinifera) varieties, these which are natives to and widely grown in Mallorca, Spain, as they are the major red and white grape varieties used in the 
local wine industry. The stems used in this study were provided by a Spanish winery (Antonio Nadal S.L., Mallorca). Stems were obtained directly at the beginning of the winemaking process after the grape desteming process. Samples were dried, ground and stored at $-20^{\circ} \mathrm{C}$ until used.

The following standards and reagents were used: Stable free radical DPPH (2,2-diphenyl-1-picrylhydrazyl) was obtained from Aldrich, Germany. Folin-Ciocalteau reagent was purchased from Merck, Germany. (+)Catechin and DL- $\alpha$-tocopherol from Sigma, Spain, and gallic acid from Aldrich, Germany.

All reagents used were of analytical grade.

Dry matter was determined by drying the samples to a constant weight at $105^{\circ} \mathrm{C}$.

\subsection{Preparation of Extracts}

Extracts from grape stems were prepared using two solvents ethanol: water $(80 / 20, v / v)$, in some cases, or acetone: water $(70 / 30, v / v)$, in the others. Grape stems were extracted twice with the selected solvent at room temperature for 1 hour with continuous stirring in each case. The ratio of solvent used was $10 \mathrm{~mL}$ per gram of sample. After centrifugation, supernatants were combined, concentrated at $40^{\circ} \mathrm{C}$ and lyophilised. The solid dry extracts were subjected to successive analyses.

\subsection{Determination of Total Polyphenols and Flavanols}

Total polyphenols were spectrophotometrically determined in the solid dry extracts by reading the absorbance at $765 \mathrm{~nm}$ (Folin-Ciocalteau method) [10], using gallic acid as a standard and expressing the results as gallic acid equivalents (GAE).

Flavanols were quantified in the solid dry extracts by the vanillin assay [11], using $(+)$-catechin as standard and expressing the results as $(+)$-catechin equivalents (CAE).

\subsection{Determination of Antioxidant Activity}

The antioxidant activity of the solid extracts was measured in terms of radical scavenging ability, according to the DPPH method reported by Brand-Williams et al. [12], modified by Sánchez-Moreno et al. [13]. The $\mathrm{EC}_{50}$ parameter, which reflects $50 \%$ depletion of DPPH freeradical, was expressed as grams of dry extract per gram of DPPH. This characteristic parameter is called efficient concentration $\left(\mathrm{EC}_{50}\right)$ or oxidation index, and the lower the value, the higher the antioxidant activity of the examined product. For rational reasons of clarity, the antiradical activity $\mathrm{A}_{\mathrm{AR}}$ was determined as the inverse value of the efficient concentration $\mathrm{EC}_{50}$, representing a comparable term for the effectiveness of antioxidant and radical scavenging capacity: $\mathrm{A}_{\mathrm{AR}}=1 / \mathrm{EC}_{50}$. The larger the $\mathrm{A}_{\mathrm{AR}}$, the more efficient is the antioxidant. For comparison purposes, the efficient concentrations of vitamin $\mathrm{C}$ and vitamin $\mathrm{E}$ were also evaluated.

\subsection{Statistical Analysis}

The determinations of total polyphenols and flavanol contents, and the antioxidant activity were carried out at least in quadruplicate. Results are presented as the mean value with the standard deviation (SD). Correlation between total polyphenols and flavanol contents and antioxidant activity was verified by the determination coefficient $R^{2}$ of the linear regression.

\section{Results and Discussion}

\subsection{Yield, Total Polyphenolic and Flavanol Content of Solid Extracts}

Table 1 shows the yield obtained for all the grape stem extracts from red and white grape stems. The values were close to $30 \%$ of grape stem dry weight $(27.3 \%-32.1 \%)$. Concentration of total polyphenols and flavanols obtained for the grape stems extracts are shown in Table 1 and are referred to as $\mathrm{g}$ to $100 \mathrm{~g}$ dry matter $(\mathrm{dm})$.

The solid extracts obtained from an $80 \%$ ethanol extraction process are RS-ETOH (from red grape stem) and WS-ETOH (from white grape stem) and those corresponding to $70 \%$ acetone extraction process are RSACET (from red grape stem) and WS-ACET (from white grape stem).

The high polyphenolic content for all the grape stem extracts can be observed in Table 1. The quantities of total polyphenols present in the red grape stem extracts were higher than those of the white stem extracts, independent of the solvent used. Concentrations of total polyphenols in the RS-ETOH and RS-ACET extracts were equal to 29.4 and 38.4 (g GAE/100g dm), respectively; whereas the quantities of polyphenols contained in

Table 1. Yield, total polyphenols and flavanols of grape stem extracts.

\begin{tabular}{cccc}
\hline $\begin{array}{c}\text { Solid } \\
\text { Extract }\end{array}$ & $\begin{array}{c}\text { Yield } \\
(\% \mathrm{dm})\end{array}$ & $\begin{array}{c}\text { Polyphenols } \\
(\mathrm{g} \mathrm{GAE} / 100 \mathrm{~g} \mathrm{dm})\end{array}$ & $\begin{array}{c}\text { Flavanols } \\
(\mathrm{g} \mathrm{CAE} / 100 \mathrm{~g} \mathrm{dm})\end{array}$ \\
\hline RS-ETOH & $29.5 \pm 0.6$ & $29.4 \pm 0.4$ & $21.7 \pm 0.3$ \\
WS-ETOH & $27.3 \pm 0.5$ & $17.2 \pm 0.2$ & $12.6 \pm 0.2$ \\
RS-ACET & $30.1 \pm 0.6$ & $38.4 \pm 0.5$ & $27.0 \pm 0.4$ \\
WS-ACET & $32.1 \pm 0.6$ & $22.9 \pm 0.3$ & $16.2 \pm 0.2$ \\
\hline
\end{tabular}

Results are expressed as the mean $(n=4) \pm S D ; G A E=$ gallic acid equivalent; $\mathrm{CAE}=$ catechin equivalent; $\mathrm{RS}-\mathrm{ETOH}=$ solid extract from red grape stem with $80 \%$ ethanol; WS-ETOH $=$ solid extract from white grape stem with $80 \%$ ethanol; RS-ACET $=$ solid extract from red grape stem with $70 \%$ acetone; WS-ACET $=$ solid extract from white grape stem with $70 \%$ acetone. 
the related extracts obtained from white grape stem, WS-ETOH and WS-ACET, were 17.2 and 22.9 (g GAE/ $100 \mathrm{~g} \mathrm{dm})$, respectively. This fact is in accordance with the higher polyphenolic content of the red grape stem variety Manto Negro in opposite to the white grape stem variety Prensal Blanc previously described, 11.6 and 8.7 g GAE/100g dm, respectively [2,4]. Püssa et al. [14] reported that red varieties stems have higher polyphenol values than those of white varieties.

Moreover, Table 1 illustrates that the acetone extracts obtained from either grape stem varieties were richer in polyphenols than that the ethanol extracts. In fact, for the extracts corresponding to the red grape stem, RS-ACET was richer than RS-ETOH (38.4 to $29.4 \mathrm{~g} \mathrm{GAE} / 100 \mathrm{~g} \mathrm{dm}$, respectively), and analogously, for extracts corresponding to the white grape stem, WS-ACET was richer than WS-ETOH (22.9 to $17.2 \mathrm{~g} \mathrm{GAE} / 100 \mathrm{~g} \mathrm{dm}$, respectively).

Therefore, the results show the high polyphenolic content for all the solid grape stem extracts obtained in this work that are between $17.2 \%$ and $38.4 \%$ of dm (Table 1).

Additionally, Table 1 gives the flavanol content of the grape stems extracts. Similar in pattern to the results shown above for the polyphenols, the flavanol content of the red grape stem extracts, RS-ETOH and RS-ACET, were higher than that in the white stem extracts, WS-ETOH and WS-ACET (21.7 and $27 \mathrm{~g} \mathrm{CAE} / 100 \mathrm{~g} \mathrm{dm}$ compared to 12.6 and $16.2 \mathrm{~g} \mathrm{CAE} / 100 \mathrm{~g} \mathrm{dm}$, respectively). Again, the acetone extract obtained from either red or white grape stem varieties was richer in flavanols than that the ethanol extract.

Notable is the high flavanol content for all the stem extracts obtained. Table 1 clearly shows that flavanols accounted for approximately $70 \%$ of the polyphenolic content of white and red grape stem extracts.

Summarizing, the best grape stem extract for either total polyphenol or flavanols contents was that obtained from a red grape stem, using $70 \%$ acetone as solvent.

\subsection{Antioxidant Activity}

Table 2 shows the antioxidant activity of red and white grape stem extracts expressed as effective concentration, $\mathrm{EC}_{50}$, antiradical activity, $\mathrm{A}_{\mathrm{AR}}$ and antioxidant activity equivalents of vitamin $\mathrm{C}$ and vitamin $\mathrm{E}$. All solid extracts obtained presented a high antioxidant activity, especially the red grape stem extracts, RS-ACET and RS-ETOH, which have an $\mathrm{EC}_{50}=0.14$ and $0.20 \mathrm{~g} \mathrm{dm} / \mathrm{g} \mathrm{DPPH}$, respectively, representing an antiradical activity $\mathrm{A}_{\mathrm{AR}}$ of 7.14 and $5 \mathrm{~g} \mathrm{DPPH} / \mathrm{g} \mathrm{dm}$, respectively. These high antioxidant activities correspond to 615 and 430 vitamin $C$ mg-equivalent/g dm, respectively, and 1630 and 1140 vitamin E mg-equivalent/g dm, respectively. Note that both extracts had an antioxidant activity higher than that vitamin E. On the other hand, the extracts obtained from the white grape stem, WS-ACET and WS-ETOH, had an $\mathrm{EC}_{50}=0.26$ and $0.37 \mathrm{~g} \mathrm{dm} / \mathrm{g} \mathrm{DPPH}$, respectively, representing an antiradical activity $\mathrm{A}_{\mathrm{AR}}$ of 3.85 and $2.70 \mathrm{~g}$ $\mathrm{DPPH} / \mathrm{g} \mathrm{dm}$, respectively. They corresponded to 331 and 233 vitamin $\mathrm{C}$ mg-equivalent/g dm, respectively, and 878 and 616 vitamin $\mathrm{E} \mathrm{mg}$-equivalent/g dm, respectively.

The grape stem extract with a higher antioxidant activity was that obtained from red grape stem using $70 \%$ acetone as solvent. Is should be noted that this follows that same trend as in the cases of total polyphenols and flavanols previously mentioned.

In fact, antioxidant activity was closely correlated with the total content of polyphenols and flavanols. So, by linear regression analysis, there is a significant correlation between the total content of polyphenols and the antioxidant activity of the grape stem extracts studied. The linear equation resulting was: Polyphenols content $=$ 48.801 - $89.962 \mathrm{EC}_{50}$ (determination coefficient, $\mathrm{R}^{2}=$ 0.9352) (negative slope due to the lower the $\mathrm{EC}_{50}$ value, the higher the antioxidant activity). This fact was described by several authors in selected fruits, vegetables and grain products, tea infusion, Rubus species and vine grapes and leaves [15-18]. These authors found a significant correlation between the total content of polyphenols and the antioxidant power.

Moreover, there is a significant correlation between the flavanols content and the antioxidant activity of thegrape stem extracts studied and the linear equation re-

Table 2. Effective concentration $\mathrm{EC}_{50}$, antiradical activity $\mathrm{A}_{\mathrm{AR}}$ and antioxidant activity equivalents of vitamins $\mathrm{C}$ and $\mathrm{E}$ of grape stem extracts.

\begin{tabular}{ccccc}
\hline Solid Extract & $\mathrm{EC}_{50}(\mathrm{~g} \mathrm{dm} / \mathrm{g} \mathrm{DPPH})$ & $\mathrm{A}_{\mathrm{AR}}\left(1 / \mathrm{EC}_{50}\right)$ & $\begin{array}{c}\text { AA-Vit C eq (ascorbic acid) } \\
\text { (vit. C mg-eq/g dm) }\end{array}$ & $\begin{array}{c}\text { AA-Vit E eq (DL- } \alpha \text {-tocopherol) } \\
\text { (vit. E mg-eq/g dm) }\end{array}$ \\
\hline RS-ETOH & $0.20 \pm 0.02$ & $5.00 \pm 0.50$ & 430 & 1140 \\
WS-ETOH & $0.37 \pm 0.04$ & $2.70 \pm 0.29$ & 233 & 616 \\
RS-ACET & $0.14 \pm 0.01$ & $7.14 \pm 0.71$ & 615 & 1630 \\
WS-ACET & $0.26 \pm 0.03$ & $3.85 \pm 0.44$ & 331 & 878 \\
\hline
\end{tabular}

Results are expressed as the mean $(\mathrm{n}=4) \pm \mathrm{SD}$; AA-Vit $\mathrm{C}$ eq $=$ Antioxidant activity-vitamin $\mathrm{C}$ equivalent; AA-Vit $\mathrm{E}$ eq $=$ Antioxidant activity-vitamin $\mathrm{E}$ equivalent; RS-ETOH $=$ solid extract from red grape stem with $80 \%$ ethanol; WS-ETOH $=$ solid extract from white grape stem with $80 \%$ ethanol; RS-ACET $=$ solid extract from red grape stem with $70 \%$ acetone; WS-ACET $=$ solid extract from white grape stem with $70 \%$ acetone. 
sulting was: Flavanols content $=34.550-62.588 \mathrm{EC}_{50}$ (determination coefficient, $\mathrm{R}^{2}=0.9404$ ).

The use of natural polyphenols from grape stem as food additives can be advantageous. It is well known that the maximum lawful levels for synthetic food antioxidants are established from different toxicological parameters that need not be applicable to naturally occurring compounds. Therefore, the polyphenols from natural extracts could be used at higher levels than the synthetic phenols, thereby increasing their antioxidant effectiveness. Also, the anti-oxidative characteristics of these natural compounds can represent an interesting feature for their application to prevent deterioration of pharmaceuticals and cosmetics.

\section{Conclusions}

The high contents in total polyphenols as well as in flavanols together with the excellent antioxidant properties of all the grape stem extracts obtained confer a wide range of applications of these products in food, cosmetic and pharmacological industries.

Taking into account that grapes are used on the order of millions of tons in wine producing countries, the results for these four solid extracts obtained from wine grape stems indicate an abundant and valuable source of natural antioxidant sources in which their utilization could also provide at least a partial solution for the winemaking waste.

\section{Acknowledgements}

The author gratefully acknowledge the financial support from the Comunitat Autònoma de les Illes Balears (Conselleria d'Agricultura i Pesca de la CAIB).

\section{REFERENCES}

[1] P. Doshi, P. Adsule and K. Banerjee, "Phenolic Composition and Antioxidant Activity in Grapevine Parts and Berries (Vitis vinifera L.) cv. Kishmish Chornyi (Sharad Seedless) during Maturation," International Journal of Food Science and Technology, Vol. 41, 2006, pp. 1-9. doi:10.1111/j.1365-2621.2006.01214.x

[2] A. Llobera and J. Cañellas, "Dietary Fibre and Antioxidant Activity of Manto Negro Red Grape (Vitis vinifera): Pomace and Stem," Food Chemistry, Vol. 101, No. 2, 2007, pp. 659-666. doi:10.1016/j.foodchem.2006.02.025

[3] D. P. Makris, G. Boskou and N. K. Andrikopoulos, "Polyphenolic Content and in Vitro Antioxidant Characteristics of Wine Industry and Other Agri-Food Solid Waste Extracts," Journal of Food Composition and Analysis, Vol. 20, No. 2, 2007, pp. 125-132. doi:10.1016/j.jfca.2006.04.010

[4] A. Llobera and J. Cañellas, "Antioxidant Activity and Dietary Fibre of Prensal Blanc White Grape (Vitis vinifera) By-Products," International Journal of Food Science and Technology, Vol. 43, No. 11, 2008, pp. 1953-1959. doi:10.1111/j.1365-2621.2008.01798.x

[5] M. G. L. Hertog, "Flavonols and Flavones in Foods and Their Relation with Cancer and Coronary Heart Disease Risk," Ph.D. Thesis, Agricultural University Wageningen, the Netherlands, 1994.

[6] E. N. Frankel, "Food Antioxidants and Phytochemicals. Present and Future Perspectives," Fett-Lipid, Vol. 101, No. 12, 1999, pp. 450-455. doi:10.1002/(SICI) 1521-4133(199912)101:12<450::AIDLIPI450>3.0.CO;2-8

[7] C. Rice-Evans, "Flavonoid Antioxidants," Current Medicinal Chemistry, Vol. 8, No. 7, 2001, pp. 797-807.

[8] L. Lurton, "Grape Polyphenols: New Powerful Health Ingredients," Innovations in Food Technology, Vol. 18, 2003, pp. 28-30.

[9] E. M. Choi and J. K. Hwang, "Screening of Indonesian Medicinal Plants for Inhibitor Activity on Nitric Oxide Production of RAW264.7 Cells and Antioxidant Activity," Fitoterapia, Vol. 76, No. 2, 2005, pp. 194-203. doi:10.1016/j.fitote.2004.11.010

[10] V. L. Singleton and J. A. Rossi Jr., "Colorimetry of Total Phenolics with Phosphomolybdic -Phosphotungstic Acid Reagents," American Journal of Enology and Viticulture, Vol. 16, 1965, pp. 144-158.

[11] H. P. S. Makkar, "Quantification of Tannins in Free Foliage: A Laboratory Manual for the FAO/IAEA Co-Ordinated Research Project on Use of Nuclear and Related Techniques to Develop Simple Tannin Assay for Predicting and Improving the Safety and Efficiency of Feeding rumiants on the Tanniniferous Tree Foliage," Joint FAO/ IAEA Division of Nuclear Techniques in Food and Agriculture, Vienna, 1999, pp. 1-29.

[12] W. Brand-Williams, M. E. Cuvelier and C. Berset, "Use of a Free Radical Method to Evaluate Antioxidant Activity," Lebensmittel Wissenschaft und Technologie, Vol. 28, No. 1, 1995, pp. 25-30. doi:10.1016/S0023-6438(95)80008-5

[13] C. Sanchez-Moreno, J. A. Larrauri and F. Saura-Calixto, "A Procedure to Measure the Antiradical Efficiency of Polyphenols," Journal of the Science of Food and Agriculture, Vol. 76, No. 2, 1998, pp. 270-276.

doi:10.1002/(SICI)1097-0010(199802)76:2<270::AID-JS FA945>3.0.CO;2-9

[14] T. Püssa, J. Floren, P. Kuldkepp and A. Raal, "Survey of Grapevine Vitis Vinifera Stem Polyphenols by Liquid Chromatography-Diode Array Detection-Tandem Mass Spectrometry," Journal of the Agricultural and Food Chemistry, Vol. 54, No. 20, 2006, pp. 7488-7494. doi:10.1021/jf061155e

[15] Y. S. Velioglu, G. Mazza, L. Gao and B. D. Oomah, “Antioxidant Activity and Total Phenolics in Selected Fruits, Vegetables, and Grain Products," Journal of the Agricultural and Food Chemistry, Vol. 46, No. 10, 1998, pp. 4113-4117. doi:10.1021/if9801973

[16] I. F. F. Benzie and Y. T. Szeto, "Total Antioxidant Capacity of Teas by Ferric Reducing/Antioxidant Power Assay," Journal of the Agricultural and Food Chemistry, 
Vol. 47, No. 2, 1999, pp. 633-636. doi:10.1021/jf9807768

[17] N. Deighton, R. Brennan, C. Finn and H. V. Davies, “Antioxidant Properties of Domesticated and Wild Rubus Species," Journal of the Science of Food and Agriculture, Vol. 80, No. 9, 2000, pp. 1307-1313. doi:10.1002/1097-0010(200007)80:9<1307::AID-JSFA63
8>3.0.CO;2-P

[18] J. Balik, M. Kyselakova, N. Vrchotova, J. Trista, M. Kumsta, J. Veverka, P. Hic, J. Totusek and D. Lefnerova, "Relations between Polyphenols Content and Antioxidant Activity in Vine Grapes and Leaves," Czech Journal of Food Sciences, Vol. 26, 2008, pp. S25-S32. 